Henning Bergenholtz*

\title{
Leksikologiske analyser og beskrivelser ctr. leksikografiske angivelser \\ Bemærkninger til Undine Kramer: Lexikologisch- lexikographische Aspekte der deutschen Gegenwartssprache. Berlin 2000
}

\begin{abstract}
A lexicographer is not always a linguist. And a linguist is not a natural expert or semiexpert of lexicography. This is also the case for such lexicologists who see themselves as theoretical lexicographers. More important than such relationships are the negative consequences which a purely linguistic argumentation may have for lexicographical theory and practice. In many cases lexicological reviews of dictionaries and their proposals for better dictionaries are far removed from real lexicographical needs and improvements. This will be shown in a critical review of a recent publication about lexicologicallexicographical aspects.
\end{abstract}

\section{Leksikografiske principper}

De forhåbninger, som dele af den videnskabelige verden $\mathrm{i}$ anden halvdel af 1960erne havde til den teoretiske lingvistik, viste sig hurtigt at være urealistiske. I stedet for en udvikling til en superlingvistik skete der en findeling af lingvistikken i en lang række bindestregslingvistikker. Derudover flyttede mange lingvister deres arbejdsområde til nabodiscipliner som semiotik og leksikografi. For leksikografien har disse lingvister haft en altafgørende betydning for fagets rivende teoretiske udvikling. Det er derfor ikke overraskende, at de fleste universitetsansatte metaleksikografer er tilknyttet institutter for sprog, men man finder også mange praktiske leksikografer, oftest fagleksikografer, $i$ alle andre videnskabs-

* Prof. Dr. Henning Bergenholtz.

Handelshøjskolen i Arhus

Center for leksikografi

Fuglesangs Allé 4

DK-8210 Aarhus $V$

E-mail:HB@ASB.DK 
grene. Metaleksikografiens rivende udvikling har dog - netop på grund af lingvisters overvægt - haft en lingvistisk-strukturalistisk overvægt med det resultat, at mange metaleksikografiske bidrag snarere har været relevante for lingvistikken end for leksikografien. Min negative bedømmelse af lingvistikkens indflydelse på leksikografien deles ikke af ret mange leksikografer med en lingvistisk baggrund. Den gængse holdning, som ser leksikografien som en del af lingvistikken, er forbundet med en overvurdering af lingvistikkens betydning for leksikografien. Typisk er følgende holdning:

"A great deal of the basic lexicographical principles is motivated from theoretical linguistics." (Lombard 1994: 213)

Som lingvist kunne jeg glæde mig over, at den teoretiske lingvistik menes at have en direkte indflydelse på leksikografisk teori og praksis. Men som leksikograf har jeg svært ved at genkende en sådan beskrivelse af den teoretiske lingvistiks rolle for leksikografien. Selvfølgelig bliver lingvistiske termer for ordklasser, fleksion, ordforbindelser brugt i ordbøger og i metaleksikografisk litteratur - men som i lingvistikken uden en fælles normeret terminologi og derfor meget forskelligt. Brugen af disse termer er vel næppe det, Lombard mener, når han taler om leksikografiske principper. Hvad han ellers kan have ment, er ikke så let at gætte. Jeg kan i hvert fald ikke påpege nogen væsentlige leksikografiske principper, som klart bygger på den teoretiske lingvistiks resultater. Det gælder i særdeleshed for leksikografiske strukturteorier (især makrostruktur, mikrostruktur, tilgangsstruktur og mediostruktur). Det gælder også for alle principper for brugerunders $\emptyset$ gelser og for principielle overvejelser om ordbøgers funktioner hhv. summen af ordbogsfunktioner, som kaldes genuint formål. Og endelig gælder det, at den teoretiske lingvistik kun har spillet en marginal rolle for fagleksikografiens teori og praksis.

Derimod svarer fortsættelsen af ovenstående citat til virkeligheden, til leksikologers brug af ordbøger i deres forskning:

"It is also the case that lexicographers and dictionaries can present linguists with a systematical source of real language for the solution of practical problems.“ (Lombard 1994: 213)

Dette er en korrekt gengivelse af den praksis, hvor mange leksikologer i høj grad bruger ordbøgers oplysninger som udgangspunkt for leksikologiske analyser. Som denne artikel også vil påpege, er nogle lek- 
sikologers kritik af mangler i ordbøger netop lingvistisk og ikke leksikografisk begrundet. Visse leksikologers krav om indarbejdelse af en lang række specielle semantiske oplysninger, som „mangler“ i foreliggende ordbøger, tager ikke udgangspunkt i en bestemt ordbogstypes genuine formål. Derimod ville det være fordelagtigt for den praktiske leksikografi, hvis lingvister, i højere grad end tilfældet er, ville stille nøjagtige empiriske analyser til rådighed for leksikografien, fx om grammatiske forhold, sml. Bergenholtz (1995a).

\section{Leksikologisk-leksikografiske aspekter}

Dette bindestregsudtryk er misvisende, et misfoster skabt af lingvister, som tænker mere på lingvistik end på leksikografi. Der findes en lang række bøger med en sådan titel. Jeg vil i det følgende tage nogle eksempler fra en af de nyeste med en gennemgående brug af dette udtryk: Kramer (2000) med titlen Lexikologisch-lexikographische Aspekte der deutschen Gegenwartssprache. Bogen indeholder 12 bidrag, ca. halvdelen skrevet af leksikologer. Sådan set er titlen derfor korrekt, men den relaterer sig ikke til forfatternes udgangspunkt i leksikologi hhv. leksikografi. Man kan formode, at titlen bygger på den udbredte opfattelse af leksikografi som praktisk leksikologi, dvs. leksikologien som det teoretiske fundament og leksikografien som et af områderne, hvor leksikologiske teorier og analyser bruges, således også Kjær (1995: 3). Selvom denne opfattelse er den gængse, svarer den ikke til leksikografisk teori og praksis, se hertil fx Wiegand (1989), Bergenholtz (1995b) og Tarp (1998). Heller ikke alle bidragsyderne i Kramer (2000) deler denne opfattelse, fx gør Wiegand (2000) det helt sikkert ikke.

Et tydeligt eksempel på en leksikologisk, men ikke nødvendigvis en leksikografisk problemstilling er Ewald Langs bidrag om mennesker vs. folk ("Menschen vs. Leute") (Lang 2000). Lang konstaterer kritisk, at ingen ordbog forklarer, om eller hvornår de to ord kan bruges på samme måde, og slet ikke, hvori forskellen mellem dem består. Langs kritik er principielt korrekt, men deraf følger ikke, at en ordbogs kvalitet kan bedømmes på, hvor godt den gengiver sprogvirkeligheden ved ordforrådets grundenheder som folk og mennesker (Lang 2000: 36). Det er et interessant lingvistisk problem, men ikke nødvendigvis et relevant problem for enhver ordbog. En ordbog er et stykke værktøj, og det skal som alt værktøj bedømmes efter, hvor godt det kan bruges til at løse de 
opgaver, som værktøjet er beregnet til at klare.

Det er heller ikke indlysende, at ordbøger altid bliver bedre, hvis de klart skelner mellem verden og sprog (Lang 2000: 33, 36). Tværtimod har det ikke bare socialhistoriske grunde, at man på tysk ikke taler om Aufwartemann, Trümmermann eller Aufwarteleute og Trümmerleute, men kun om Aufwartefrau og Trümmerfrau. Nej, leksikografiske definitioner af Trümmerfrau og Aufwartefrau tager nødvendigvis udgangspunkt i verden og den måde, man sprogligt forholder sig til denne verden. Vi har på dansk kun brandmaend til at slukke ild. Hvis man taler om brand$k v i n d e r$, slukker de ikke ilden, men tænder den i tilbedernes hjerter, se hertil Bergenholtz/ Frandsen (2001). Anderledes er det i Tyskland, hvor ordbøger gengiver den normale sprogbrug og med to forskellige opslagsord skelner klart mellem Feuerwehrfrau und Feuerwehrmann. Det er således lettere at udarbejde en leksikografisk definition til Feuerwehrmann og -frau i en tysk ordbog end til brandmand i en dansk ordbog. Her burde man evt. i en produktionsordbog tilføje, at der i Danmark ganske vist findes kvinder i brandvæsenet, men de kaldes brandmand, og at brandkvinder eller -damer findes ikke i brandvæsenet.

Ewald ville sikkert mene, at en sådan tilføjelse ville være en absurd og overflødig encyklopædisk angivelse. Han er her enig med de fleste leksikologer, herunder Mitar Pitzek, som også bidrager i ovennævnte bog om leksikologisk-leksikografiske aspekter om det tyske nutidssprog. Pitzek (2000: 53) betegner følgende ordbogsartikel som ,ein[e] ins Absurde gehende Bedeutungserklärung“, den har efter hans mening alt for mange encyklopædiske oplysninger:

Papaya ... Frucht des Papayabaumes, die einer Melone ähnlich sieht, birnenförmig, mit orangefarbenem Fruchtfleisch u. Milchsaft in gelblich-weißer Färbung u. kleinen runden, schwarzen, glänzenden, weichen Kernen in der Mitte (ordbogsartikel 1)

Som kontrast hertil betegner Pitzek følgende ordbogsartikel som ,eine übersichtliche, minimal-kontrastive Bedeutungserklärung“, en efter hans mening langt bedre ordbogsartikel:

Papaya ... Frucht des Melonenbaums (ordbogsartikel 2)

Denne ordbogsartikel svarer til de oplysninger, man finder i DanskOrdbogen (1999). Her findes der ved den ene ortografiske variant ingen form for betydningsangivelse, kun en henvisning til den anbefalede. Ved den anden variant findes ikke nogen leksikografisk definition, men en 
synonymangivelse, som indholdsmæssigt svarer til den korte leksikografiske definition i ordbogsartikel (2):

papaya $\rightarrow$ papaja (ordbogsartikel 3)

papaja subst <en, -en, -er, -erne > = papajafrugt (ordbogsartikel 4)

Den sidstnævnte ordbog er konciperet som en tekstproduktionsordbog for brugere, som har dansk som modersmål. Det er altså ikke en receptionsordbog, som skal være til hjælp ved problemer med tekstreception. Hvis brugeren slet ikke ved, hvad en papaja er, vil denne næppe bruge ordet. Men når brugeren kender ordet - evt. lært det som del af en anden ordbogsartikel - kan han få bekræftet, at papaja eller papaya er det samme som papajafrugt. Brugeren kan også under lemmaet papajatra få bekræftet, at det er noget andet en papaja hhv. papajafrugt. Dette ord har i DanskOrdbogen (1999) to betydninger:

papajatræ ...

1. melontræ

2. papajatræets ved (ordbogsartikel 5)

Den mere udførlige leksikografiske definition i ordbogsartikel (1) er efter min mening udmærket, hvis ordbogsbrugerne vil vide, hvad ordet betyder, hvis han læser det i en tekst og ikke forstår det. En sådan ordbogsfunktion kaldes tekstrelateret med specifikationen tekstreception af en bruger med tysk som modersmål. Denne artikel kan også bruges, hvis ordbogsbrugeren er lægmand i relation til frugter og vil vide noget om papajafrugten. Denne ordbogsfunktion kaldes vidensrelateret; den er ikke tekstrelateret, idet det ikke drejer sig om et problem, som skal løses i forbindelse med textreception, tekstproduktion eller oversættelse, men som tekstuafhængig videnstilegnelse eller -udvidelse.

En konkret ordbog kan være konciperet som en polyfunktional ordbog med præcis de to nævnte funktioner, dvs. en (tekstrelateret) reception af tyske tekster for modersmålsbrugere og et (vidensrelateret) tekstuafhængigt ønske om ny eller yderligere viden for lægfolk skrevet på tysk. Men man kunne også vælge at udarbejde monofunktionale ordbøger, som fx DanskOrdbogen (1999), der udelukkende har funktionen dansk tekstproduktion for modersmålsbrugere.

Uden nøjagtige overvejelser om en bestemt ordbogs genuine formål, dvs. mængden af ordbogsfunktioner, vil overvejelser som de nævnte af Lang (2000) og Pitzek (2000) forblive leksikografisk golde og i bedste fald leksikologisk interessante. Det gælder også for mange leksikologers 
og leksikografers problemer med at skelne mellem viden om verden og viden om sprog. Dette kan evt. være relevant i leksikologisk sammenhæng, det afhænger af den valgte leksikologiske teori, men ikke i leksikografien.

\section{Encyklopædiske og semantiske angivelser}

De to nævnte leksikologer er enige $i$, at det er vigtigt at skelne mellem oplysninger om verden og om sprog, om encyklopædiske og semantiske angivelser, hvor de såkaldte sprogordbøger kun skal anføre semantiske angivelser. Men de to forfattere er ikke særligt klare i deres fremstilling, hvilket til dels, men ikke kun hænger sammen med brugen af den uhensigtsmæssige term sprogordbog (se hertil Bergenholtz/ Kaufmann 1996). Pitzek (2000) viser med eksemplet papaja, hvad han opfatter som en semantisk hhv. som en encyklopædisk angivelse. Lang (2000: 32) er på samme tid enig og uenig med Pitzeks skarpe opdeling. Lang anser en klar skelnen som yderst vigtig, men antager også en flydende grænse (,verschwommene Grenzlinie“) mellem en encyklopædisk og en semantisk angivelse.

En større klarhed skaber Wiegand (1988 og 1994). Han skelner mellem semantisk og encyklopædisk viden, som dog ikke skal adskilles med en grænse, men i stedet have en overgangszone. På denne måde opstår en opdeling i tre vidensområder, hvor område (2) er den fælles overgangszone:

(1) ikke-encyklopædisk betydningsviden

(2) encyklopædisk genstandskonstituerende betydningsviden

(3) encyklopædisk betydningsviden.

Til eksemplet citron giver Wiegand (1988) følgende forklaring: Som ikke-encyklopædisk betydningsviden (1), dvs. rent semantisk viden kan siges, at det drejer sig om en substantivisk prædikator, som usuelt bliver brugt refererende og/eller præciserende. Som encyklopædisk betydningsviden (3) kan fx anføres, at citroner i dag er billige. I overgangszonen mellem semantik og encyklopædi anføres to slags encyklopædisk genstandskonstituerende betydningsviden: (2a) Kategorividen, $\mathrm{fx}$ at en citron er en frugt, og at citron er et næringsmiddel, (2b) stereotypviden, $\mathrm{fx}$ at citroner er gule, og at citroner er saftige.

Wiegands teoretiske overvejelser om relationerne mellem semantik og encyklopædi har fundet stor tilslutning i den nyere metaleksikografiske 
litteratur. Blandt de få kritikere kan nævnes Bergenholtz (1994), Rossenbeck (1994), Bergenholtz/ Kaufmann (1996) og Geeb (1997). Jeg må dog trække min kritik tilbage, hvis Kammerer (2000: 287f) har ret i sit forsvar for Wiegands fremstilling og heraf følgende kritik af Bergenholtz/ Kaufmann (1996). Kammerer mener, at også meget udførlige leksikografiske definitioner skal forstås som encyklopædisk genstandskonstituerende betydningsviden, fx også den næsten to sider lange leksikografiske definition af bakteriofag, som Bergenholtz/ Kaufmann (1996) foreslår for en vidensrelateret ordbog for semieksperter. Kammerer vil med denne begrundelse derfor også måtte anse både ordbogsartikel (1), (2), (5) og også de nedenstående ordbogsartikler (6) og (7) som eksempler på angivelser med en encyklopædisk genstandkonstituerende betydningsviden. I alle tilfælde udgør Wiegands opdeling og medtagelse af encyklopædiske dele i en leksikografisk definition et stort fremskridt, som fx Lang (2000) og Pitzek (2000) ikke følger. Tværtimod viser Wiegand (1994) og også Bergenholtz (1995b), at en skelnen mellem semantik og encyklopædi ikke er egnet som princip for medtagelse eller udeladelse af oplysning om betydning.

Når leksikologer bruger ordbøgers angivelser sker det sjældent som en ren overtagelse fra ordbøgerne, men ofte i form af en kritisk forbedring. Man kan så diskutere, om det drejer sig om forbedringer. Wierzbicka (1993: 49) kritiserer fx følgende ordbogsartikel:

dentist a person who is skilled in and licensed to practise the prevention, diagnosis, and treatment of diseases, injuries, and malformations of the teeth, jaws, and mouth and who makes and inserts false teeth (ordbogsartikel 6)

Denne artikel er ifølge Wierzbicka alt for udførlig, da den ikke hører hjemme i en ordbog, men i en encyklopædi. I en ordbog, siger hun, står der noget om betydning, i en encyklopædi noget om almen viden ("knowledge and meaning"). I stedet for foreslår Wierzbicka en kort definition til en ordbog:

dentist someone whose job is to look after teeth (ordbogsartikel 7)

Jeg er enig $i$, at ordbogsartikel (6) ikke er vellykket. Men det er ikke pga. den angivelige medtagelse af encyklopædiske forstyrrelser, men pga. den uklare lange opremsning. Ordbogsartikel (7), leksikologens eget forslag til leksikografisk praksisforbedring er dog endnu mindre vellykket. Det er ikke en dårlig leksikografisk definition, fordi den angiveligt har 
udeladt al encyklopædisk "st øj", men fordi artiklen er direkte misvisende og i øvrigt meget mere uklar end den af Wierzbicka kritiserede ordbogsartikel (6). Wierzbicka nævner ikke med ét ord, for hvem eller til hvilken brugersituation, ordbogsartikel (7) skal være egnet. Jeg prøver selv at opfinde et par muligheder:

Oskar er ved at skrive brev, hvor han vil berette om sin bedstefar, der skal have skiftet sine forlorne tænder ud. Nu har Oskar ikke engelsk, men dansk som modersmål og bruger derfor en dansk ordbog, som har ordbogsartikler svarende til Wierzbickas leksikologiske forslag. Oskar ved ikke sikkert, om bedstefaren skal til en tandlæge, en tandtekniker eller en tandplejer. Han slår først op under tandlage. Indholdet af ordbogsartikel (7) viser, at han kan bruge dette ord. Oskar har fået løst sit problem, svaret er blot ikke korrekt. Et sådant arbejde udføres af en tandtekniker, som i dag normalt vil have en uddannelse som laboratorietandtekniker. I øvrigt må man vel gå ud fra, at både tandtekniker og tandplejer havde fået præcis samme leksikografiske definition som anført i ordbogsartikel (7). Så hvis Oskar i stedet havde slået op under tandtekniker, ville han have valgt det rigtige ord. Hvis han havde slået op under alle tre ord, ville han med samme leksikografiske definition i alle tre tilfælde troet, at de betød præcis det samme og havde så valgt et af dem. Wierzbickas leksikografiske forslag er klart svagere end den af hende kritiserede ordbogsartikel (6).

Hvis det i stedet drejer sig om et receptionsproblem, kan man bedømme ordbogsartikel (7) lidt mere positivt. Vi vælger her en anden bruger og en anden brugersituation: Muhammed, som har opholdt sig i Danmark, kan noget dansk, men har ikke noget stort dansk ordforråd, hverken passivt eller aktivt. Han har fået nogle papirer, hvor der nævnes ordet tandlcege. Hvad er det, tænker Muhammed, og slår op i sin ordbog, som er en forklarende dansk lørnerordbog, der har en dansk udgave af ordbogsartikel (7). Muhammed har fået sit problem løst, ganske vist ikke med en særlig præcis angivelse, men i første omgang er det en tilstrækkelig oplysning til at kunne forstå teksten så nogenlunde. Men muligvis tror Muhammed, at en tandlæge ikke selv borer eller renser tænder. Så heller ikke i denne brugssituation er ordbogsartikel (7) helt vellykket.

Hvis det derimod drejer sig om en ikke-teksrelateret brugersituation, er ordbogsartikel (7) helt utilstrækkelig. For at illustrere denne påstand kan vi beholde samme bruger som i ovenstående brugersituation. Muham- 
med har nu lært, hvad en tandlæge er, men han har også set ordet tandtekniker, som stod på et skilt ved indgangen til en dør ved siden af busstoppestedet. Hvad er nu forskellen mellem tandtekniker og tandlage, vil Muhammed vide? Han bruger sin lørnerordbog og mener heraf at kunne se, at de to ord må betyde det samme, da der ca. står det samme under tandtekniker.

Hvis Muhammed i stedet havde brugt Nudansk Ordbog i udgaven fra 1992, havde han ganske vist ikke fået noget svar, men til gengæld heller ikke et ufuldstændigt og misvisende svar. Denne ordbog, beregnet for modersmålsbrugere, forklarer slet ikke de mest kendte ord, herunder tandlage:

tandlæge subst. en; -n, -r, -rne (ordbogsartikel 8)

Til tekstproduktion for en dansker er det vel heller nødvendigt, næppe mange danskere vil, når de læser eller vil bruge ordet tandlæge, slå det op i en ordbog, fordi de ikke kender betydningen af det. Hvis ordet skal forklares som hjælp ved ønske om en vidensudvidelse eller -præcisering, kunne det ske som i Nudansk Ordbogs sidste udgave (Nudansk Ordbog 1999):

tandlæge en person som er uddannet i undersøgelse, behandling og pleje af tænder, fx reparation af huller i tænderne, rodbehandlinger og tandudtrækninger $=$ odontolog, cand. odont. (ordbogsartikel 9)

Der kunne her have været en yderligere angivelse af, at det drejer sig om en akademisk uddannelse, men det ses indirekte gennem synonymangivelsen „,cand. odont.“. Alt i alt er det en korrekt angivelse, som dog sandsynligvis sjældent bliver brugt af danske modersmålsbrugere ved receptions- og tekstproduktionsproblemer.

\section{Leksikologi ctr. leksikografi}

En udførligere beskrivelse af forskellige former for betydningsbeskrivelse til forskellige ordbogsfunktioner kan ikke gives her. Jeg mener ikke, at leksikografiske definitioner i foreliggende ordbøger er optimale. Tværtimod viser praksis i mange monolingvale ordbøger, at de givne leksikografiske definitioner hverken er velegnede til de tekstrelaterede funktioner reception og produktion eller den ikke-tekstrelaterede vidensudvidende funktion. En polyfunktional ordbog, der mener at kunne tilgodese alle 
tre nævnte grundfunktioner som primære og ligeværdige funktioner, vil normalt ikke kunne være optimal i valg af leksikografisk definition. Derimod kan man med fordel foretage en prioritering, så man i en tekstproduktionsordbog for modersmålsbrugere kun forklarer svære ord og forskelle mellem betydningsnære ord. I en sådan ordbog vil denne funktion være primær og både den tekstrelaterede funktion reception og den vidensrelaterede funktion sekundær (se fx ordbogsartikel 2, 3, 4, 5 og 8). Omvendt kan man i en anden ordbog, som konciperes som polyfunktional, have to primære hovedfunktioner: tekstreception og den ikketekstrelaterede vidensudvidelse. Her kan en sådan ordbog have den tekstrelaterede funktion produktion som den sekundære (se fx ordbogsartikel 1 og 6). Derimod taler ikke meget for at lytte til leksikologers velmente råd. Snarere må der advares mod mange råd fra denne kant (se ordbogsartikel 2 og 7).

\section{Litteratur}

Bergenholtz, Henning (1994). Faglige oplysninger i monolingvale betydningsordbøger. In LexicoNordica 1. 13-26.

Bergenholtz, Henning (1995a). Grammatik i bilingvale ordbøger. In LexicoNordica 2. 5-18.

Bergenholtz, Henning (1995b). Leksikografi. Hvad er det? In Svararsdóttir, Åsta, Kvaran, Gudrun \& Jónsson, Jón Hilmar (red.) (1995). Nordiske Studier i leksikografi 3. Rapport fra Konference om leksikografi i Norden. Reykjavik 7.-10. juni 1995. Reykjavik: Nordisk forening for leksikografi. 37-49.

Bergenholtz, Henning \& Frandsen, Susanne (2001). Ordbogen om kvinden. København: Forum.

Bergenholtz, Henning \& Kaufmann, Uwe (1996). Enzyklopädische Informationen in Wörterbüchern. In Weber, Nico (Hg.) (1996). Theorie der Semantik und Theorie der Lexikographie. Tübingen: Niemeyer. 168-182.

DanskOrdbogen (1999) = Bergenholtz, Henning, Pedersen, Jette, Vrang, Vibeke \& Almind, Richard (1999). DanskOrdbogen. Århus: Systime.

Geeb, Franziskus (1997). Semantische und enzyklopädische Informationen in Fachwörterbüchern. Eine Untersuchung zu fachinformativen Informationstypen mit besonderer Berücksichtigung wortgebundener Darstellungsformen. PhD-afhandling. Århus: Handelshøjskolen i Århus.

Kammerer, Matthias (2000). Lemmazeichentypen für deutsche Verben. Eine lexikologische und metalexikographische Untersuchung. Tübingen: Niemeyer.

Kjær, Anne Lise (1995). Einleitung. In Kromann, Hans-Peder \& Kjær, Anne Lise (Hgg.) (1995). Von der Allgegenwart der Lexikologie. Kontrastive Lexikologie als Vorstufe 
zur zweisprachigen Lexikographie. Tübigen: Niemeyer. 1-6.

Kramer, Undine (Hg.) (2000). Lexikologisch-lexikographische Aspekte der deutschen Gegenwartssprache. Tübingen: Niemeyer.

Lang, Ewald (2000). Menschen vs. Leute: Bericht über eine semantische Expedition in den lexikalischen Nahbereich. In Kramer (2000). 1-40.

Lombard, F.J. (1994). Lexicographer, Linguist and Dictionary User: An uneasy Triangle. In Lexikos 4. 204-214.

Nudansk Ordbog (1992) = Politikens Nudansk Ordbog. Bd. 1 A-K. Bd. 2 L-Å. 15. udg. København: Politikens Forlag.

Nudansk Ordbog (1999) = Politikens Nudansk Ordbog. 17. udg. København: Politikens Forlag.

Pitzek, Mitar (2000). Anmerkungen zur lexikographischen Bedeutungserklärung in allgemeinen einsprachigen Wörterbüchern. In Kramer (2000). 41-58.

Rossenbeck, Klaus (1994). Enzyklopädische Informationen im zweisprachigen Fachwörterbuch. In Schaeder, Burkhard \& Bergenholtz, Henning (Hgg.) (1994). Fachlexikographie. Fachwissen und seine Repräsentation in Wörterbüchern. Tübingen: Narr. 133-159.

Tarp, Sven (1998). Leksikografi på egne ben. Fordelingsstrukturer og byggedele i et brugerorienteret perspektiv. In Hermes 2. 121-137.

Wiegand, Herbert Ernst (1988). Was eigentlich ist Fachlexikographie? Mit Hinweisen zum Verhältnis von sprachlichem und enzyklopädischem Wissen. In Munske, H.H. et al. (Hgg.) (1988). Deutscher Wortschatz. Lexikologische Studien. Ludwig Erich Schmitt zum 80. Geburtstag von seinen Marburgern Schülern. Berlin, New York: de Gruyter. 729-790.

Wiegand, Herbert Ernst (1989). Die lexikographische Definition im allgemeinen einsprachigen Wörterbuch. In Hausmann, Franz Josef, Reichmann, Oskar, Wiegand, Herbert Ernst \& Zgusta, Ladislav (Hgg.) (1989). Wörterbücher. Dictionaries. Dictionnaires. Ein internationales Handbuch zur Lexikographie. An International Encyclopedia of Lexicography. Encyclopédie internationale de lexicographie. Erster Teilband. Berlin, New York: de Gruyter. 530-588.

Wiegand, Herbert Ernst (1994). Zur Unterscheidung von semantischen und enzyklopädischen Daten in Fachwörterbüchern. In Schaeder, Burkhard \& Bergenholtz, Henning (Hgg.) (1994). Fachlexikographie. Fachwissen und seine Repräsentation in Wörterbüchern. Tübingen: Narr. 103-132.

Wiegand, Herbert Ernst (2000). Verschmelzungen in allgemeinen einsprachigen Wörterbüchern des Deutschen. In Kramer (2000). 59-96.

Wierzbicka, Anna (1993). What Are the Uses of Theoretical Lexicography? In Dictionaries. Journal of the Dictionary Society of North America 14. 44-78. 
